\title{
The Effect of YouTube Reviews on Video Game Sales
}

\author{
Feray ADIGÜZEL iD a \\ a LUISS University, Business and Management Department, ferayadiguzel14@hotmail.com
}

\begin{tabular}{|c|c|}
\hline ARTICLE INFO & ABSTRACT \\
\hline $\begin{array}{l}\text { Keywords: } \\
\text { YouTube video reviews }\end{array}$ & $\begin{array}{l}\text { Purpose - This study examines the effects of consumer engagement behaviour towards game reviews } \\
\text { posted on YouTube on video game sales. }\end{array}$ \\
\hline $\begin{array}{l}\text { Consumer engagement } \\
\text { behaviour } \\
\text { Influencers } \\
\text { Critic reviews } \\
\text { Consumer reviews }\end{array}$ & $\begin{array}{l}\text { Design/methodology/approach - An empirical research was conducted after analyses of } 140 \text { YouTube } \\
\text { reviews about top games selected from the video games titles released within 2010-2019. The impacts } \\
\text { of social media engagement activities (total views, the ratio of likes/dislikes to total views, review } \\
\text { sentiment) of YouTube reviews, consumer and critic reviews on games sales were investigated with } \\
\text { ordinary least square (OLS) regression model. }\end{array}$ \\
\hline $\begin{array}{l}\text { Received } 12 \text { February } 2021 \\
\text { Revised } 17 \text { July } 2021 \\
\text { Accepted } 25 \text { July } 2021\end{array}$ & $\begin{array}{l}\text { Findings-The findings indicated that consumer engagement behaviour of YouTube reviews } \\
\text { significantly influenced sales; however, the effect is not larger than critics' and consumers' text reviews. } \\
\text { Consumer reviews have the highest positive impact on sales. YouTube review sentiment did not } \\
\text { influence sales and YouTube reviews posted by an influencer (i.e., user) compared to a firm (i.e., } \\
\text { marketing generated) did not have higher sales. }\end{array}$ \\
\hline $\begin{array}{l}\text { Article Classification: } \\
\text { Research Article }\end{array}$ & $\begin{array}{l}\text { Discussion - The results draw attention to the importance of engaging video game reviews on } \\
\text { YouTube and consumers' and critics' online textual reviews for video games sales. This research } \\
\text { contributes three streams of research: Digital word of mouth, consumer engagement behaviour on social } \\
\text { media and predicting video game sales. The contribution is to indicate the predictive power of } \\
\text { engagement of YouTube game reviews on game sales, to compare reviewer type (user/influencer - } \\
\text { versus firm-generated) and to compare the effectiveness of video reviews to textual critic and consumer } \\
\text { reviews. }\end{array}$ \\
\hline
\end{tabular}

\section{Introduction}

The video gaming industry is a huge and very dynamic industry and reported to have worth $\$ 159.3$ Billion in 2020 and continue in growth is expected due to the extensive effects of corona pandemic increase ${ }^{1}$. This industry is accepted as the most profitable industry in the entertainment sector and the impact of video games market was expected to increase (Marchand, 2016). Indeed, players' total revenue reached 880 million dollars in 2020 in Turkey and the number of game players has been reported as 36 million (Turkey Game Market Report, 2020). Gamers have high purchasing power and appear to be more tech-savvy than non-gamers (Flores-Méndez et al., 2018). Gamers are also defined to be highly influential listeners. Indeed, majority of YouTube channels with the most subscribers are gaming-related. Gamers subscribe to gaming-related channels, watch video games' reviews and even engage with videos by commenting, liking, subscribing or sharing on YouTube. Some enthusiastic gamers who can be called as gaming influencers, even create their own review videos and upload on their YouTube channel to be a YouTube influencer or to help other gamers and communicate with them. Increasing profits of video gaming industry indicate why gaming influencers are increasing in numbers. Video reviews of games on YouTube might be either created by a gamer (i.e., user-generated) or a firm such as a game developer firm, game magazines, a digital marketing firm (i.e., marketing-generated). So far, the effects of online textual reviews written by critics or consumers on performance of video games have been investigated in terms of valence and volume in marketing literature. However, video game reviews on YouTube might have a strong impact on game sales considering that gamers are tech-savvy and very likely spend more time on YouTube. Besides, there is a need for investigating the influence of YouTube content on performance of video game sales. This study fills-in this void focusing on game review videos posted on YouTube, and identifies post type, namely user- vs firm-

${ }^{1}$ https://www.theverge.com/2021/1/6/22215786/video-games-covid-19-animal-crossing-among-us 
generated, extracts sentiment within a review video and compares effectiveness of them to the textual online reviews.

Video games differ from other product categories as being an experience good similar to movies and books. The quality of an experience good are difficult to observe in advance and consumers can examine product quality only after consumption. Therefore, product reviews are crucial to signal quality of any experience products and they influence the success of experience goods (Cox \& Kaimann, 2015). Recommendations from other users and professionals potentially have stronger impact on video games' sales compare to movie sales (Zhu \& Zhang, 2010). First of all, the variety of video games are higher than the variety of movies (Zhu \& Zhang, 2010), and therefore a game player would need more quality signals to identify a good game from many. Time investment for a video game is higher than a movie or music song. Besides, a video game is typically higher-priced than a music or movie (Zhu \& Zhang, 2010). Too many choice options of game titles, increased time and money investments increase the importance of reviews on video games sales. A game review could be an online textual review or a video on YouTube. A YouTuber gamer can indicate gameplay, comment, and rate a game in his/her YouTube video. Video reviews might be more effective compare to written reviews of critics or users because it is more vivid and informative. In this paper, the effects of YouTube review videos created by a user (i.e., gamer) and a firm will be investigated and their effect will be compared to textual online reviews by critics and consumers. So, the research objective is to investigate the effects of YouTube review videos, and online textual reviews by critics and consumers on video game sales.

Academics give less attention to this industry compare to other well-known entertainment industries, namely movie or music industry (Marchand \& Hennig-Thurau, 2013). Although YouTube exits for fifteen years, gamers use YouTube actively and gaming-related YouTube channels have the most subscribers ${ }^{2}$, previous research about the marketing effectiveness of YouTube platform is limited compare to Twitter and Facebook. As far as this author knows, this is the first work investigating the effectiveness of video reviews on YouTube on video game sales (see Table A1). Previous studies that investigated the influence of social media platforms investigated mostly movie sales and these studies can be categorized as either using only one social media platform or multiple platforms. Studies that investigated one platform for movies were mostly used data from microblogs (Rui et al., 2013 and Hennig-Thurau et al., 2015 for Twitter; Du et al., 2014 for Tencent; Liu et al., 2016 for Sina), or from Facebook (Ding et al., 2017). Studies that examined multiple platforms for movies examined either two platforms, specifically Twitter and Facebook (Bogaert et al. 2021; Oh et al. 2017; Houston et al. 2018) or four platforms, specifically blogs, review website (Yahoo!Movies), Twitter, and YouTube (Baek et al. 2017). For video games, only study that investigated the predictive power of social media platforms was Marchand et al. (2017) and they investigated the predictive power of Twitter and product reviews on Amazon. Existing studies were concentrated on online textual reviews in movie industry. Besides, findings on the effectiveness of consumers and critics review metrics have been contradictory. Surprisingly, there is no study on the impact of YouTube reviews. YouTube is a better platform to review experience products considering being able to deliver a review with a video. Since videos are vivid and create better visual about a game experience, YouTube review videos are very likely to have a high impact on video game sales and as such, should be investigated. Besides, the wireless internet and mobile phones might lead to a fundamental shift in consumers' information acquisition about new video games and therefore the relative importance of critics and consumers and YouTube reviews might be different. Using a novel dataset of video games, this research untangles the effects of consumers, critics and YouTube video reviews on video games sales.

The topic of YouTube video reviews is a timely topic for the video gaming companies to understand the effects of YouTube video reviews for a success of a new game. Findings of this research can help game developers and video games companies to plan their marketing campaigns and spending efficiently and target the right channels for optimal sales performance. For instance, they can see whether a user- vs a company-generated video review is more effective. They can understand which format is more effective in terms of revenues: whether a written or video review.

In the next section, literature review was discussed under three sections: YouTube usage as a social media strategy, the impacts of consumers' and critics' reviews, and the influence of social media channels on video

${ }^{2}$ https://www.thinkwithgoogle.com/marketing-strategies/video/gaming-related-youtube-view-statistics/ 
game sales. Section 3 covers hypotheses argumentation. Section 4 presents the method, gives information about the research data, and reports the results. Section 5 concludes, and discusses implications of the findings.

\section{Literature Review}

\subsection{YouTube and Social Media Strategy}

Parallel to digital transformation, companies are integrating social media platforms in their advertising strategy. Both companies and consumers can create and share content about brands and products (Mangold \& Faulds, 2009; Kaplan \& Haenlein, 2009). One of those social platforms is YouTube which is an online videosharing platform. Since its establishment in February 2005 and later acquisition by Google in 2006, YouTube becomes a popular social media platform that consumers spend a lot of time on it. YouTube is the second most-visited website after Google Search. YouTube users can view, rate, share, add to playlists, report, upload, comment on videos and subscribe to other users at YouTube. Users who create content and have grown large followings on digital platforms, such as YouTube, LinkedIn and Twitter have started to attract interests of companies as an endorsement opportunity.

Influencer marketing was defined as a collaboration of companies with third party endorsers to promote for their brands and products (De Veirman, Cauberghe \& Hudders, 2017). Game developers and video game firms are forward thinking and they have quickly grasped the commercial potential of these new generation influencers who appeal to a large community. They can give incentives for influential gamers who are active on social media platforms, specifically YouTube to review their new games. They can digitally advertise their products on these YouTube channels. Tracking user comments or sentiment on YouTube review videos can give an idea about how to fix problems in a gameplay, or how to select right games to distribute. Engagement statistics of game related YouTube videos as a measure of buzz can give an idea on sales performance of a new game.

\subsection{The influence of online consumer and critic textual reviews}

There is an agreement on positive impact of reviews written by either professionals or consumers on sales: For instance, for movies (Eliashberg \& Shugan, 1997; Basuroy et al., 2003; Reinstein \& Snyder, 2005; Souza et al., 2019), for video games (Zhu \& Zhang, 2010; Cox \& Kaiman, 2015), and for books (Chevalier \& Mazylin, 2006). However, findings on significance of eWOM metrics, namely valence, volume and variance and the relative importance of critic vs user reviews have been contradictory. Valence is about whether a review contains overall positive, negative or neutral feelings. It can be operationalized as rating, sentiment, favourability or polarity. Volume is about the quantity of reviews. The number of reviews is the most common way to measure volume, and it can show how popular the product is. Variance of review ratings as an eWOM metric was less investigated and it indicates the heterogeneity in consumer opinions (Sun, 2012).

Consumer review (valence) was found to be more important than critic reviews for movies (Chintagunta, 2010) and for video games (Zhu \& Zhang, 2006, 2010). However, later research indicated the impact of customer reviews are overstated and critic reviews valence is more important than customer review valence for movies (Basuroy et al., 2019) and for video games (Cox \& Kaimann, 2015).

Volume of reviews were discussed as the most important performance factor by researchers (Liu, 2006; Duan et al., 2008; Cui et al., 2012). Recently, two meta studies claimed opposite effects for volume and valence effects. While You et al. (2015) indicated that volume have lower impact on sales than valence, Babic et al. (2016) showed the opposite effect: volume has a stronger effect on sales than valence. Cox and Kaimann (2015) found that all critic related variables (valence, volume and consistency i.e., variance) contributed positively to sales of video games. This paper examines the impacts of critic and consumer reviews' valence and volume one more time for video games while also taking account the effect of video reviews on YouTube.

\subsection{The influence of social media channels and video game sales}

Marchand et al. (2017) examined the impacts of Twitter and Amazon consumer reviews and Metacritic critic reviews on video game sales over time. The effects of Twitter and Amazon consumer reviews on new video game sales change over time. The valence of microblogging (Twitter) was not significant influence throughout the product lifetime, but the valence of consumer reviews did towards the end. The volumes of microblogs, consumer reviews, and advertising was shown to drive early week sales. The volume of microblogs is initially 
effective after the release and later impact drops. On the other hand, there is a continuous growth in the impact of the volume of consumer reviews. Baek et al. (2017) compared the influence of four social media channels on movie sales in terms of volume: Twitter, Yahoo!Movies, YouTube, and blogs. The influence of Twitter and Yahoo!Movies on sales was larger at the early stage and at the late stage of a movie's opening, respectively; however, no differences in sales were observed for blogs and YouTube at the early and late stage of a movie's opening. The impacts of consumer engagement behaviours on Twitter, Facebook and YouTube on movie sales was investigated by Oh et al. (2017). They defined two types of engagement behaviour in the paper: personal which is intrinsically motivated and interactive which is both intrinsically and extrinsically motivated. While consumers involve in personal engagement passively consume the content such as likes or views, consumers involve in interactive engagement discuss and share their opinions about movies with others and indicate sharing, commenting, retweeting type behaviours. Their findings indicated significant positive relationship between consumer engagement behaviours on YouTube, Facebook and box office gross revenues, but the same effect was not significant on Twitter. Oh et al. (2017) studied movie industry instead of video games industry and they did not cover the influence of online textual consumer and critic reviews. Houston et al. (2018) investigated the effect of consumer generated pre-release buzz data from Twitter (volume) and Facebook (volume of likes) on opening week movie sales. Pre-release buzz meaning buzz that occurs earlier to commercial introduction of a new product, has conceptually a multidimensional construct with three dimensions: Communication, search and participatory behaviour in the paper. Houston et al. (2018) obtained that Twitter (communication dimension of pre-release buzz) has a larger effect than Facebook (participatory behaviour dimension of pre-release buzz). This paper differs from their study in three aspects: Oh et al (2017) considered only pre-release buzz, it was for movies and it did not cover YouTube. Recently, Bogaert et al. (2021) investigated the predictive power of Facebook and Twitter on movie box office sales. The influence of Facebook on box office sales was larger than Twitter because Twitter users had less source credibility than Facebook users. Another recent study proved that Facebook engagement of a movie trailer had a higher positive effect on movie sales than YouTube engagement of a movie trailer (Adıgüzel, 2021). Besides, YouTube has a larger effect at earlier stage of a movie screen while Facebook is more effective at late stage of a movie screen. So far, the type (user- versus firm-generated), volume and sentiment of audio-visual game reviews posted on YouTube on video games sales were not investigated and this paper fills-in this void.

\section{Hypothesis Argumentation}

Companies have realized the potential benefits of a product review by an influencer to increase product awareness and to generate sales. Consumers often search for like-minded amateurs' opinions in various ways. Interactive, engaging and easy to watch video reviews help gaming influencers to build their communities. "Influencers" can be described as are people or organizations that can sway the public opinion to change their decision on a purchase. They have typically very high reach on social media platforms, such as YouTube or Instagram. Influencers are well-connected, create an impact, have active minds, and are trendsetters (Keller \& Berry, 2003). Consumers develop a long-lasting relationships with influencers (Lee \& Watkins, 2016; Munnukka et al., 2019) and therefore influencers have loyal followers.

Consumers might trust reviews of YouTube video game influencers more than critic and consumer reviews with the following reasons. First, consumers might think that YouTube video game influencers have more knowledge and experience than ordinary video gamers but their tastes are more similar compare to professional critics. Previous research indicated that critics and ordinary consumers have different tastes and preferences. Experts have elite tastes and take into account a greater extent the technical or artistic aspects of the product (Goldenberg et al., 2006; Holbrook, 2005). For instance, independent movies take more positive reviews by experts, but not ordinary moviegoers. Ordinary video gamers might find more similarity with themselves and YouTube influencers (homophily effect) compare to professional critics and ordinary consumers and therefore they can find information given by them as more trustworthy and reliable. Similar people can inspire trust. Studies on social networking discussed attitude homophily, meaning the degree to which people tend to bond with similar others, as an explanatory factor of influence-based relationships patterns and interpersonal communications (Aral \& Walker, 2012,2014). Sokolova and Kefi (2020) investigated Instagram and YouTube bloggers and found that attitude homophily is positively related to para-social interaction meaning the relationship between a spectator and a performer (Horton \& Wohl, 1956). Para-social interaction and credibility of the influencers are positively related to purchase intention in their research. 
Previous research concluded that influencers positively influence brand attitudes and purchase intentions (Jin \& Phua, 2014; Lee \& Watkins, 2016; Djafarova \& Rushworth, 2017). User generated videos was shown to have a greater effect on attitude toward the ad and brand compare to brand-generated videos (Diwanji \& Cortese, 2020). Overall, YouTube video reviews created by a game influencer is very likely increase game sales more than the one by a firm due to high para-social interaction between an influencer and a consumer and high credibility of an influencer. Viewers trust an influencer and rely on them for an accurate information due to influencer's expertise (Ladhari et al., 2020). Besides, friendly, casual and more personal video reviews by influencers have the ability to keep viewers engaged (Delbaere et al. 2021). Thus, the first hypothesis is the following:

\section{H1: YouTube video posted by an influencer have higher game sales than YouTube video posted by a firm}

YouTube enable engagement with the video content through watching, liking or disliking, commenting, sharing the video content, following and subscribing to video channels. YouTube enabled engagement can be positively associated with a video game performance. Previous research indicated that consumers' offline behaviours are positively related with likes on Facebook (Mochon et al., 2017) and purchase decisions (Bhattacharyya \& Bose, 2020). In a movie context, sharing a movie trailer on YouTube was proved to influence movie performance (Oh et al., 2017). Recent study also proved the positive relationship between pre-release engagement on social media channels, namely Twitter, Facebook and YouTube, and opening week movie sales (Castillo et al., 2021). Consumers experience a movie by watching a movie trailer in a shortened form and this experience influence their movie/going decision. Similarly, game reviews in a video format give opportunity to experience a new game before purchase and give a chance to reduce information asymmetries between buyers and sellers. Besides, YouTube video reviews are high-quality visual content similar to Instagram and succeed to engage viewers intensely (Pentina et al., 2018). High number of views and likes to a video review indicate the content appeals to the viewers and the content is successful to catch attention. While likes indicate consumers agree with the video content and interested, dislikes can still indicate attention but disagreement with the content. So, increased consumer engagement behaviours are indicators for increased attention, interest and agreement or disagreement with the content, game sales might increase positively.

\section{H2: There is a positive relationship between consumer engagement behaviours on YouTube and game sales.}

In a digital age, online consumers are impatient with the content presented in a text format and therefore they prefer to watch a video instead of reading a text when searching for product-related information ${ }^{3}$. Videos can carry more vivid information with visuals about a new video game more than written review texts. Vivid information means any piece of information which helps consumers to induce physical and experiential aspect of a product (Flavian et al., 2017). Pictures, audio-visual content (i.e., videos) and colourful exemplars are examples of vivid information. Vivid information was proved to influence directly mental imagery processing and product evaluations and intentions (Orus et al, 2016). Video reviews provide an opportunity to see the product in action. Video reviews supply more realistic and richer information about a new game and therefore they are more persuasive compare to textual reviews. An experimental study by Albano, Guerreiro and Rita (2019) also illustrated that video reviews increase purchase intentions more than text reviews. Next to the advantage of creating imagery about a product experience, product reviews in video format has the advantage of providing interaction possibility compare to textual product reviews. Daugherty et al. (2008) stated that online content that is both visual and auditory is more vivid compared to online textual content. The content of YouTube review videos is both auditory and visual.

Gamers can like or dislike a video review, write a comment, share it with others and click to the related product link for further product information. There is not much chance of further interaction with textual product reviews. Sales of a product is very likely increase with more engagement with a video product review because engagement indicates interest and involvement to a product (de Oliveira Santini et el. 2020). When positive engagement increases with a YouTube review video, consumers' purchase decisions might be higher than ordinary and expert reviews because YouTube videos provide more vivid and rich information than textual reviews and gamers can interact with a reviewer.

H3: The effect of YouTube videos on game sales is higher than the effects of ordinary and critic reviews.

${ }^{3}$ https://www.retaildive.com/news/72-of-consumers-prefer-videos-to-text-marketing/524161/ 


\section{Method}

Data was collected from multiple sources: VGChartz.com, MobyGames, Metacritic and YouTube. VGChartz data has been previously used by relevant previous research (Cox, 2014; Cox \& Kaimann, 2015). Sales data of video games between 2010 and 2019 was obtained from VGChartz. When there is missing in Total Sales, Total Shipped data was used, assuming the shipped games were sold. Differing from Cox and Kaimann (2015), global sales were used in this paper instead of only North America region. The time period was more recent 2010-2019 because the usage and importance of social media was more significant last decades as explained by Chu \& Kim (2011). Besides, the selected time period covers the latest generation of game consoles. Platform, publisher, developer, release date and duration (i.e., elapsed time since the first release) information of a new game were also obtained from VGChartz. After gathering all game specific data, the ones that had missing entries were omitted.

The game characteristics, namely genre, interactivity, being a part of an existing franchise (i.e. sequel), multiplatform release were obtained from MobyGames website. ESRB ratings were missing for some of the games, and the missing data was retrieved from the official website of ESRB. ESRB assigns age and content ratings to consumer video games and it has four categories for a video game: teen (13 years and older), everyone $10+$ (ten years and older), everyone (suitable for all ages), mature (17 years and older). There was no game with category "Adults Only 18+" in the sample.

User and critic review scores were collected from Metacritic website. Metacritic is a website that houses aggregate review scores for various forms of media (music, movies, tv series as well as video games). This paper uses the averages of both metrics that Metacritic provides under two different categories (valence of critic and user reviews), while recording the volume of reviews in each category. Metacritic gives critic review scores on a 0-100 scale, while it gives the user scores on a 0-10 scale. To be able to compare them with Cox and Kaimann's (2015) findings, user scores were rescaled on a scale of 0-100.

Top fifteen games with the highest sales were selected and up to ten YouTube videos about per selected game was searched to extract YouTube information. The total sample size of 140 YouTube videos consisted of the sample and later merged with sales, game and critic information. YouTube review videos were searched by using the keywords " $<$ Game Name $>$ review" and the topmost videos with review content has been selected. Additionally, it is safe to assume that the average user will use the default setting for their search. Considering this research analyses on the top performers, it is logical to expect their audience to be wide as well, which implies more "average users" instead of enthusiasts. YouTube variables are total view, like and dislike counts, review sentiment score and the type of YouTube reviewer. The type of YouTube reviewer was categorized after looking to review poster's profile information to understand whether the video was posted by an influencer (1) versus company (0) such as GameSpot. Sentiment analysis of video reviews was done by watching each video and assigning 1 point for a positive review, 0.5 point for a mixed review and 0 point for negative review. As most videos do not release their content in a text format to the public, using a sentiment analysis software was unfeasible.

\subsection{Variables}

The dependent variable is logarithm of total sales of a game given in VGChartz, similar to previous research (Cox et al. 2014, 2015). Since games have different release date and earliest games is very likely to have high sales, logarithm of sales will be divided by number of years passed since the first release and used as a dependent variable in analyses. Independent variables are valence and volume of critic and consumer reviews, volume (total views of a YouTube video), valence (percentage of likes/dislikes to total views) of a YouTube video, YouTube video sentiment and YouTube reviewer type. Consumer engagement behaviours were measured with volume and valence metrics.

Control variables were selected from Cox \& Kaimann's papers $(2014,2015)$ closely, by listing other possible signals of quality to account for endogeneity. Interactivity was added as suggested as an important component by Marchand (2016). Interactivity is a dummy variable, indicating the game offers any multiplayer mode (local or online). It was coded 0 if the game can be played simultaneously with other players from different locations through the Internet; 1(both) otherwise. Multiplatform (dummy) indicates whether the game is released on more than one platform (coded as 1). Remasters have not been considered as multiplatform as they are 
considered completely a new game. Genre dummies was created. There were two genres in the selected game sample: action and racing/driving. Action games are considered 1, as they make up by far the largest group in the dataset. Age restriction dummy indicates whether a game was rated as Mature (+17) by ESRB (coded as 1) and it was used by Cox et al. (2014, 2015), as well as Terry et al. (2011). However, it was not included in the final model because of high correlation with some variables.

The following ordinary regression model was fitted:

logSalesij $=\beta_{0}+\beta_{1}$ Critic Valence $+\beta_{2}$ Critic Volumei $+\beta_{3}$ Consumer Valence $+\beta_{4}$ Consumer Volumeit $\beta_{5}$ YouTubeReviewerType ${ }_{i j}+\beta_{6}$ YouTubeVideoVolume $_{i j}+\beta_{7}$ YouTubeLiketoViewe $_{i j}+$

$\beta_{8}$ YouTubeDisliketoViewe $_{i j}+\beta_{9}$ YouTubeSentiment $_{i j}+\beta_{10}$ Multiplatform $_{i}+\beta_{11}$ Sequel $_{i}+\beta_{12}$ Interactivityi $+\beta_{13}$ Genrei $+\varepsilon_{i}$

where $i$ indicates a video game title and $\mathrm{j}$ represents the YouTube video index. Standardized values will be used in regression due to different units of measurements.

\subsection{Results}

The correlation matrix and descriptive were presented in Table 1 . The three highest significant correlation with sales is valence of critic (0.46), then the ratio of likes to view count $(0.43)$ and valence of consumer reviews (0.25). The correlation between volume of consumer and critic reviews is high, 0.82 . Multicollinearity was inspected with variance inflation factors (VIF). Average VIF value was 3.26 and there were no VIF value larger than commonly recommended cut-off 10 .

Table 1. Descriptive and correlations between variables

\begin{tabular}{|c|c|c|c|c|c|c|c|c|}
\hline Variables & Mean & $\mathrm{SD}$ & 1 & 2 & 3 & 4 & 5 & 6 \\
\hline Sales (1) & 3.1 & 0.12 & 1 & & & & & \\
\hline VolumeCritic (2) & 111.08 & 3.95 & -0.13 & 1 & & & & \\
\hline ValenceCritic(3) & 87.42 & 0.63 & $0.46^{*}$ & $0.56^{*}$ & 1 & & & \\
\hline VolumeConsumer(4) & 4940 & 452 & -0.12 & $0.82^{*}$ & $0.52^{*}$ & 1 & & \\
\hline ValenceConsumer(5) & 66.49 & 1.56 & $0.25^{*}$ & $0.21^{*}$ & $0.51^{*}$ & -0.05 & 1 & \\
\hline LiketoViewYouTube(6) & 0.02 & 0.00 & $0.43^{*}$ & -0.04 & $0.25^{*}$ & 0.03 & -0.02 & 1 \\
\hline Multiplatform(7) & 0.69 & 0.04 & -0.01 & $0.38^{*}$ & 0.13 & $0.41^{*}$ & -0.53 & 0.13 \\
\hline Interactivity $(8)$ & 0.93 & 0.02 & $-0.24^{*}$ & $0.39^{*}$ & 0.05 & $0.18^{*}$ & $0.31^{*}$ & -0.34 \\
\hline Genre: Action(9) & 0.86 & 0.03 & 0.05 & $0.23^{*}$ & -0.07 & $.29^{*}$ & $-0.4^{*}$ & 0.13 \\
\hline DisliketoViewYouTube(10) & 0.00 & 0.00 & 0.11 & -0.07 & -0.03 & 0.02 & $-0.24^{*}$ & -0.09 \\
\hline ViewCountYouTube(11) & 650825 & 896 & 0.14 & $0.27^{*}$ & 0.17 & $0.22^{*}$ & 0.01 & -0.01 \\
\hline Sentiment YouTube (12) & 0.86 & 0.26 & 0.03 & 0.16 & $0.24^{*}$ & 0.06 & $0.25^{*}$ & -0.11 \\
\hline ReviewerTypeYouTub (13) & 0.40 & 0.04 & -0.11 & 0.02 & -0.10 & -0.02 & -0.01 & $0.20^{*}$ \\
\hline \multirow[t]{2}{*}{ Sequel (14) } & 0.84 & 0.03 & 0.11 & $0.23^{*}$ & $0.28^{*}$ & 0.15 & $0.19^{*}$ & -0.14 \\
\hline & 7 & 8 & 9 & 10 & 11 & 12 & 13 & 14 \\
\hline Multiplatform(7) & 1 & & & & & & & \\
\hline Interactivity $(8)$ & $-0.19^{*}$ & 1 & & & & & & \\
\hline Genre: Action(9) & 0.16 & -0.11 & 1 & & & & & \\
\hline DisliketoViewYouTube(10) & 0.14 & -0.08 & 0.07 & 1 & & & & \\
\hline ViewCountYouTube(11) & 0.15 & 0.12 & 0.16 & 0.01 & 1 & & & \\
\hline Sentiment YouTube (12) & -0.01 & 0.12 & -0.06 & -0.09 & -0.1 & 1 & & \\
\hline ReviewerTypeYouTub (13) & -0.10 & 0.11 & 0.00 & -0.09 & 0.04 & 0.01 & 1 & \\
\hline Sequel (14) & -0.15 & $0.61^{*}$ & $-0.19^{*}$ & 0.06 & 0.13 & $-.17^{*}$ & 0.04 & 1 \\
\hline
\end{tabular}

Notes. *: 0.05 significance level, SD: standard deviation 
There is model fit $(F(13,125)=65.36, p<0.001)$ and explanatory variables explained 0.87 of variance in video games sales which is satisfactory. While volume of critic reviews significantly positively influenced video games sales $(b=0.388, p<0.001)$, valence of critic reviews significantly negatively influenced sales $(b=-0.163$, $p<0.05)$. Both valence $(b=0.494, p<0.001)$ and volume $(b=0.218, p<0.01)$ of consumer reviews significant positively influenced video games sales. Volume of YouTube videos $(b=0.082, p<0.05)$ and positive engagement (like to view ratio) $(b=0.147, p<0.001)$ significantly positively influenced sales. Interestingly, negative engagement (dislike to view ratio) has also a significant positive effect on video games sales $(b=0.080$, $p<0.05)$. YouTube video sentiment $(b=-0.018, p=0.62)$ and YouTube video Type $(b=-0.086, p=0.23)$ were not significant. Additionally, being a multiplatform video game, an action genre, and being a multiplayer game increased video games sales. Thus, $\mathrm{H}_{1}$ was not confirmed and $\mathrm{H}_{2}$ was confirmed for total views and like/dislike to view ratio, but not for YouTube sentiment.

The most important significant factors of sales were being a multiplayer game, valence of consumer reviews, volume of critic reviews, being a multiplatform game, volume of consumer reviews, valence of critic reviews (negative), YouTube Like to View Ratio, being an action genre game, volume of YouTube views, and YouTube Dislike to View Ratio, respectively. So, $\mathrm{H}_{3}$ was not confirmed because the impact of valence of consumer reviews was significantly higher than any of consumers' YouTube engagement indicators.

Table 2. OLS Results (DV = video game sales)

\begin{tabular}{lll}
\hline Variables & Coefficients & p-value \\
\hline \hline Volume Critic Review & 0.388 & 0.000 \\
\hline Valence Critic Review & -0.163 & 0.024 \\
\hline Volume Consumer Review & 0.218 & 0.004 \\
\hline Valence Consumer Reviews & 0.494 & 0.000 \\
\hline YouTube Like to View Ratio & 0.147 & 0.000 \\
\hline YouTube Dislike to View Ratio & 0.080 & 0.019 \\
\hline Volume YouTube Review & 0.082 & 0.018 \\
\hline Video Review Type (1: User 0: Firm) & -0.086 & 0.228 \\
\hline YouTube Overall Sentiment & -0.018 & 0.617 \\
\hline Multiplatform & 0.707 & 0.000 \\
\hline Interactivity & -2.835 & 0.000 \\
\hline Genre: Action & 0.326 & 0.013 \\
\hline Sequel & -0.038 & 0.776 \\
\hline Constant & 1.933 & 0.000 \\
\hline
\end{tabular}

\section{Discussions and Conclusions}

This paper investigated the effects of video game reviews posted on YouTube and textual game reviews posted on product or review websites on video game sales. Critic and consumer reviews at product or review websites were in a textual form and reviews on YouTube were in a video form. Additionally, YouTube review sentiment and YouTube video type (user/influencer- vs firm-generated) were considered. The impacts of consumer engagement to a video game review in terms of views, likes and dislikes on sales were investigated. Relative effects of video and textual game reviews on game sales were compared.

The findings indicated that consumer engagement behaviours of a video review on YouTube influenced game sales positively. The number of YouTube video views, and likes and dislikes with a YouTube video review had a positive effect on video game sales, confirming the positive effects of consumer engagement behaviours on sales (Oh et al. 2017). Even dislikes of a YouTube game review have a positive effect on sales. So, dislikes also indicate buzz around a new game and they are an indicator of increased awareness of a new game. However, the sentiment of a YouTube review did not significantly influence sales. This nonsignificant impact was probably caused by measuring sentiment with only three categories, namely positive, neutral and negative. Overall, the number of YouTube views and likes/dislikes as a social media engagement indicator are important to increase sales. The results confirmed the significant effects of social media engagement on posted review content on sales in the video games context (Marchand et al. 2017). There was no difference in sales when YouTube review is posted by an influencer compared to a firm. The expectation was the effect of user- 
generated (influential) on sales will be higher than firm-generated one. Smith et al. (2012) discussed that brandrelated YouTube content differ from the one for Twitter and Facebook. Since user on YouTube focus on especially broadcasting the self (Smith et al. 2012) and the brand/product centrality might be low in their videos, their game reviews might be also less effective. Volume and valence of consumer reviews, volume of critic reviews increased sales and increase was higher for consumer reviews compare to critic reviews, confirming previous studies (Chintagunta et al. 2010; Zhu \& Zhang 2010). However, the effect of YouTube reviews was not greater than the effect of critic or consumer textual reviews as hypothesized. Gamers who follow YouTube reviewers might be more expert and fanatic gamers than casual gamers. Casual gamers might prefer to spend less time watching a video review and might prefer textual reviews. Another interesting result was the negative effect of valence of critic reviews on sales which was opposite finding of Cox and Kaimann (2015). Thus, when critics evaluate games positively, sales decreases. Since critics and consumers have different tastes and preferences, and critics take into account more on the technical or artistic aspects of the product (Goldenberg et al., 2006; Holbrook, 2005), this negative effect is not surprising.

Under all these results, volume and positive assessments of a new game by consumers, volume of critic reviews, high number of YouTube review videos, and engaging YouTube review videos can help companies to increase their game sales.

Current research contributes to three streams of research in marketing literature: Digital word of mouth, consumer engagement behaviour on social media and predicting video game sales. Digital word of mouth literature focused mostly on online consumer reviews on either retail websites such as Amazon (Chevalier \& Mayzlin 2006) or reputation platforms such as TripAdvisor (Sridhar \& Srinivasan 2012). Despite there is research about microblogs (Twitter) effects (Marchand et al 2017), this study differs from theirs by investigating YouTube review impacts. Besides, inconsistent results about relative importance of critic and consumer reviews in creative industries were investigated again (Cox \& Kaimann 2015). This study also contributed to consumer engagement behaviour in social media by extending the effort in measuring consumer engagement behaviour in YouTube. While YouTube allows to register how many users saw the video posted, Facebook or Twitter does not record this. The ratio of likes/dislikes to number of views are probably better metric to measure consumer engagement at YouTube. Besides, the effectiveness of content posted by users compared to content posted by companies and no difference was observed.

This research provided evidence to support the role of YouTube reviews as an effective communication channel for marketing managers of gaming companies and game developers. They should target to increase YouTube reviews with high consumer engagement and select reviewers with high engagement at YouTube for further publicity and promotions. Managers should also pay attention to right social media metrics to identify right reviewers. However, when they use YouTube as a video review platform, they should not forget the significant role of consumer reviews at other mediums as well. Reviews by consumers and critics should not be undervalued; because they have the highest positive effects.

Despite the interesting findings, the findings must be interpreted in view of limitations. The time series nature of data was not considered in this paper. Future researchers might use longitudinal data, perhaps also in different contexts, to validate the current framework and to get more information about time varying effects. Further studies could expand the current findings using posts on other social media sites such as Facebook, WhatsApp, Pinterest, Instagram, LinkedIn, Snapchat, Twitter, blogs, social tags. Laboratory experiments can be used to study how consumer reviews at YouTube get processed on an individual level in future. 


\section{References}

Adıgüzel, F. (2021). Consumer engagement on social media: Its dynamics and impact on box office sales. Pazarlama ve Pazarlama Araştırmaları Dergisi. Forthcoming.

Albano, P., Guerreiro, J. \& Rita, P. (2019). The Impact of Video versus Text Reviews on Consumer Intention to Purchase. 14th Iberian Conference on Information Systems and Technologies (CISTI), 1-5.

Aral, S., \& Walker, D. (2012). Identifying influential and susceptible members of social networks. Science, 337(6092):337-341

Aral, S., \& Walker, D. (2014). Tie strength, embeddedness, and social influence: a large-scale networked experiment. Management Science, 60(6), 1351-1616.

Babic, A., Sotgiu, F., de Valck, K., \& Bijmolt, T. H. (2016). The effect of electronic word of mouth on sales: A meta-analytic review of platform, product, and metric factors. Journal of Marketing Research, 53(3), 297318.

Baek, H., Oh, S., Hee-Dong Yang, H., \& Ahn, J. (2017). Electronic Word of Mouth, box office revenue and social media. Electronic Commerce Research and Applications, 22, 13-23.

Basuroy, S., Chatterjee, S., \& Ravid, S. A. (2003). How critical are critical reviews? The box office effects of film critics, star power, and budgets. Journal of Marketing, 67(4), 103-117.

Basuroy, S., Ravid, S. A., Gretz, R. T., \& Allen, B. J. (2019). Is everybody an expert? An investigation into the impact of professional versus user reviews on movie revenues. Journal of Cultural Economics, 1-40.

Bhattacharyya, S., \& Bose, I. (2020). S-commerce: influence of Facebook likes on purchases and recommendations on a linked e-commerce site. Decision Support Systems, 138 (1), 113383.

Bogaert, M., Ballings, M., van den Poel, D., \& Oztekin, A. (2021). Box office sales and social media: A crossplatform comparison of predictive ability and mechanisms. Decision Support Systems, 147, 113517.

Castillo, A. , Benitez, J., Llorens, J., \& Luo, X. (2021). Social media-driven customer engagement and movie performance: Theory and empirical, Decision Support Systems, 145, 113516

Chintagunta, P. K., Gopinath, S., \& Venkataraman, S. (2010). The effects of online user reviews on movie box office performance: Accounting for sequential rollout and aggregation across local markets. Marketing Science, 29(5), 944-957.

Chevalier, J.A. \& Mayzlin, D. (2006). The effect of word of mouth on sales: online book reviews. Journal of Marketing Research, 43(3), 345-354.

Chu, S. C., \& Kim, Y. (2011). Determinants of consumer engagement in electronic word-of-mouth (eWOM) in social networking sites. International Journal of Advertising, 30(1), 47-75.

Cox, J. (2014). What makes a blockbuster video game? An empirical analysis of US sales data. Managerial and Decision Economics, 35(3), 189-198.

Cox, J., \& Kaimann, D. (2015). How do reviews from professional critics interact with other signals of product quality? Evidence from the video game industry. Journal of Consumer Behaviour, 14(6), 366-377.

Cui, G., Lui, H. K., \& Guo, X. (2012). The effect of online consumer reviews on new product sales. International Journal of Electronic Commerce, 17(1), 39-58.

Daugherty, T., Eastin, M. S., \& Bright, L. (2008). Exploring consumer motivations for creating user-generated content. Journal of Interactive Advertising, 8(2), 16-25.

Delbaere, M., Michael, B. \& Phillips, B.J. (2021). Social media influencers: A route to brand engagement for their followers. Psychology and Marketing,38(1), 101-112

de Oliveira Santini, F., Ladeira, W.J., Pinto, D. et al. (2020). Customer engagement in social media: a framework and meta-analysis. Journal of the Academy. Marketing Science, 48, 1211-1228.

De Veirman, M., Cauberghe, V. \& Hudders, L. (2017). Marketing through Instagram Influencers: The Impact of Number of Followers and Product Divergence on Brand Attitude. International Journal of Advertising, 36 (5), 798-28.

Ding, C., Cheng, H.K., Duan,Y., \& Jin, Y. (2017). The power of the "like" button: the impact of social media on box office, Decision Support Systems, 94, 77-84.

Djafarova, E., \& Rushworth, C. (2017). Exploring the credibility of online celebrities' instagram pro_les in influencing the purchase decisions of young female users. Computers in Human Behavior, 68, 1-7.

Diwanji, V.S., \& Cortese, J. (2020). Contrasting user generated videos versus brand generated videos in ecommerce. Journal of Retail Consumer Services, 54, 102024. 
Du, J., H. Xu, H., \& Huang,X. (2014). Box office prediction based on microblog, Expert System Applications, 41, 1680-1689.

Duan, W., Gu, B., \& Whinston, A. B. (2008). Do online reviews matter? - An empirical investigation of panel data. Decision Support Systems, 45(4), 1007-1016.

Eliashberg, J., \& Shugan, S. M. (1997). Film Critics: Influencers or Predictors? Journal of Marketing, 61, 68-78.

Flavian, C., Gurrea, R., \& Orus, C. (2017). The Influence of Online Product Presentation Videos On Persuasion And Purchase Channel Preference: The Role Of Imagery Fluency And Need For Touch. Telematics and Informatics, 34(8), 1544-1556.

Flores-Méndez, M.R., Postigo-Boix, M., Melús-Moreno, J.L. et al. (2018) A model for the mobile market based on customers profile to analyze the churning process. Wireless Netw 24, 409-422.

Goldenberg, J., Donald R. Lehmann, D. R., Shidlovski,D., \& Barak, M.M. (2006). The Role of Expert versus Social Opinion Leaders in New Product Adoption. Marketing Science Institute Report No. 06-124, Cambridge, MA.

Hennig-Thurau, T., Wiertz, C. , \& Feldhaus, F. (2015). Does twitter matter? The impact of microblogging word of mouth on consumers' adoption of new movies. J. Acad. Mark. Sci., 43, 375-394

Holbrook, M. (1999). Popular Appeal versus Expert Judgements of Motion Pictures. Journal of Consumer Research, 26, 144-55.

Horton, D., \& Wohl, R.R. (1956). Mass communication and para-social interaction. Psychiatry, 19 (3), 215-229.

Houston, M.B., Kupfer, A.K., Hennig-Thurau, T., \& Spann, M. (2018). Pre-release consumer buzz. J. Acad. Mark. Sci., 46, 338-360.

Jin, S.A.A.,\& Phua, J. (2014). Following celebrities tweets about brands: The impact of twitter-based electronic word-of-mouth on consumers source credibility perception, buying intention, and social identication with celebrities. Journal of Advertising, 43, 181-195.

Kaplan, A. \& Haenlein, M. (2009). Users of the world, unite! The challenges and opportunities of Social Media. Business Horizons, 53(1), 59-68.

Keller, E. \& Berry,J. (2003). The Influentials, Free Press.

Ladhari, R., Massa, E., Skandrani, H. (2020). YouTube vloggers' popularity and influence: The roles of homophily, emotional attachment, and expertise. Journal of Retailing and Consumer Services, 54, 102027.

Lee, J. E., \& Watkins, B. (2016). YouTube vloggers' influence on consumer luxury brand perceptions and intentions. Journal Business Research, 69, 5753-5760.

Liu, Y. (2006). Word of mouth for movies: Its dynamics and impact on box office revenue. Journal of marketing, 70(3), 74-89.

Liu, T., Ding, X., Chen, Y. , Chen, H., \& Guo, M. (2016). Predicting movie box-office revenues by exploiting large-scale social media content, Multimed. Tools Appl. 75, 1509-1528

Mangold, W.G. \& Faulds, D.J. (2009) Social media: the new hybrid element of the promotion mix. Business Horizons, 52(4), 357-365.

Marchand, A. (2016). The power of an installed base to combat lifecycle decline: The case of video games. International Journal of Research in Marketing, 33(1), 140-154.

Marchand, A., \& Hennig-Thurau, T. (2013). Value creation in the video game industry: Industry economics, consumer benefits, and research opportunities. Journal of Interactive Marketing, 27(3), 141-157.

Marchand, A., Hennig-Thurau, T., \& Wiertz, C. (2017). Not all digital word of mouth is created equal: Understanding the respective impact of consumer reviews and microblogs on new product success. International Journal of Research in Marketing, 34(2), 336-354.

Mochon, D., Johnson, K., Schwartz, J., \& Ariely, D. (2017). What Are Likes Worth? A Facebook Page Field Experiment, Journal of Marketing Research. 54(2), 306-317

Moon, S., Bergey, P. K., \& Iacobucci, D. (2010). Dynamic effects among movie ratings, movie revenues, and viewer satisfaction. Journal of Marketing, 74(1), 108-121.

Munnukka, J., Maity, D., Reinikainen, H., \& Luoma-aho, V. (2019). Thanks for watching. The effectiveness of YouTube vlogendorsements. Comput. Hum. Behav. 93, 226-234

Oh, C., Roumani, Y., Nwankpa, J. K., \& Hu, H.F. (2017). Beyond likes and tweets: Consumer engagement behaviour and movie box office in social media. Information \& Management. 54, 25-37. 
Orus, C. Flavian, C., \& Gurrea, R. (2016). Facilitating imaginations through online product presentation videos: effects on imagery fluency, product attitude and purchase intention. Electronic Commerce Research, 17, $661-700$

Pentina, I., Guilloux,V., Micu, A. (2018). Exploring social media engagement behaviors in the context of luxury brands. Journal of Advertising, 47 (1), 55-69

Reinstein, D.A. \& Snyder, C.M. (2005). The influence of expert reviews on consumer demand for experience goods: A case study of movie critics. Journal of Industrial Economics, 53(1), 27-51.

Rui, H. , Liu, Y., \& Whinston, A. (2013). Whose and what chatter matters? The effect of tweets on movie sales. Decision Support Systems, 55, 863-870.

Souza, T. L. D., Nishijima, M., \& Fava, A. C. P. (2019). Do consumer and expert reviews affect the length of time a film is kept on screens in the USA? Journal of Cultural Economics,43(1), 145-171.

Smith A.N., Fischer E., \& Yongjian C. (2012). How Does Brand-related User-generated Content Differ across YouTube, Facebook, and Twitter? Journal of Interactive Marketing, 26(2), 102-113.

Sokolova, K. \& Kefi, H. (2020). Instagram and YouTube bloggers promote it, why should I buy? How credibility and parasocial interaction influence purchase intentions, J. Retail. Consumer Serv., 53, 1-9

Sun, M. (2012). How does the variance of product ratings matter? Management Science. 58(4), 696-707.

Sridhar, S. \& Srinivasan, R. (2012). Social Influence Effects in Online Product Ratings. Journal of Marketing, 76 (5), 70-88

Terry, N., Butler, M., \& De'Armond, D. A. (2011). The determinants of domestic box office performance in the motion picture industry. Southwestern Economic Review, 32, 137-148.

Turkey Game Market Report (2020). Received from https://www.gaminginturkey.com/en/turkey-gamemarket-report-2020-has-been-published/ Accessed 15 July 2021.

You,Y. Vadakkepatt, G.G. \& Joshi, A.M. (2015). A meta-analysis of electronic word-of-mouth elasticity. Journal of Marketing, 79 (2) (2015), pp. 19-39

Zhu, F., \& Zhang, X. (2006). The influence of online consumer reviews on the demand for experience goods: The case of video games. ICIS 2006 Proceedings, 25

Zhu, F., \& Zhang, X. (2010). Impact of online consumer reviews on sales: The moderating role of product and consumer characteristics. Journal of Marketing, 74(2), 133-148. 
Appendix

Table A1. Studies of digital WOM and social media platforms on sales and contribution

\begin{tabular}{|c|c|c|c|c|c|c|c|c|c|}
\hline & & $\begin{array}{l}\text { Video } \\
\text { Reviews } \\
\end{array}$ & Video Type & Textual $\mathrm{R}$ & eviews & Social Med & a Platform & & \\
\hline Source; Method & Context & $\begin{array}{l}\text { Video } \\
\text { reviews } \\
\text { included? } \\
\end{array}$ & $\begin{array}{l}\text { User vs firm } \\
\text { generated } \\
\text { video? }\end{array}$ & $\begin{array}{l}\text { Critic } \\
\text { reviews? }\end{array}$ & $\begin{array}{l}\text { Consumer } \\
\text { reviews? }\end{array}$ & YouTube? & Twitter? & Facebook? & $\begin{array}{l}\text { Review or } \\
\text { retail } \\
\text { website? } \\
\end{array}$ \\
\hline $\begin{array}{l}\text { Eliashberg\& } \\
\text { Shugan 1997; OLS }\end{array}$ & Movies & No & No & Yes & No & No & No & No & No \\
\hline $\begin{array}{l}\text { Basuroy et al. 2003; } \\
\text { Time series OLS }\end{array}$ & Movies & No & No & Yes & No & No & No & No & No \\
\hline $\begin{array}{l}\text { Chevalier\&Mayzlin } \\
\text { 2006; Diff-in-diff }\end{array}$ & Books & No & No & No & Yes & No & No & No & Yes $^{a}$ \\
\hline $\begin{array}{l}\text { Duan et al. 2008; } \\
\text { Simul.system } \\
\text { equation }\end{array}$ & Movies & No & No & No & Yes & No & No & No & Yes $^{b}$ \\
\hline $\begin{array}{l}\text { Chintagunta et al. } \\
\text { 2010; GMM, IV }\end{array}$ & Movies & No & No & Yes & Yes & No & No & No & Yes $^{b}$ \\
\hline $\begin{array}{l}\text { Moon et al. 2010; } \\
\text { Stepwise OLS }\end{array}$ & Movies & No & No & Yes & Yes & No & No & No & Yesc $^{c}$ \\
\hline $\begin{array}{l}\text { Zhu \& Zhang 2010; } \\
\text { Diff-in-diff }\end{array}$ & $\begin{array}{l}\text { Video } \\
\text { games }\end{array}$ & $\mathrm{No}$ & No & No & Yes & No & No & No & Yes $^{\mathrm{d}}$ \\
\hline $\begin{array}{l}\text { Rui et al., (2013); } \\
\text { Dynamic panel }\end{array}$ & Movies & No & No & No & No & No & Yes & No & No \\
\hline $\begin{array}{l}\text { Du et al. (2014); } \\
\text { SVM }\end{array}$ & Movies & No & No & No & No & No & Yes(Tencent) & No & No \\
\hline $\begin{array}{l}\text { Hennig-Thurau et } \\
\text { al. (2015); OLS }\end{array}$ & Movies & No & No & Yes & No & No & Yes & Yes & No \\
\hline $\begin{array}{l}\text { Cox and Kaimann } \\
\text { 2015; GMM }\end{array}$ & $\begin{array}{l}\text { Video } \\
\text { games }\end{array}$ & No & No & Yes & Yes & No & No & No & Yes $^{\mathrm{f}}$ \\
\hline
\end{tabular}


Liu et al. (2016);

\begin{tabular}{|c|c|c|c|c|c|c|c|c|c|}
\hline OLS and SVM & Movies & No & No & No & No & No & Yes (Sina) & No & No \\
\hline Oh et al. 2017; OLS & Movies & No & No & No & No & Yes & Yes & Yes & No \\
\hline $\begin{array}{l}\text { Ding et al. 2017; } \\
\text { OLS }\end{array}$ & Movies & No & No & No & No & No & No & Yes & No \\
\hline $\begin{array}{l}\text { Baek et al. 2017; } \\
\text { OLS }\end{array}$ & Movies & Yes & No & No & No & Yes & Yes & No & Yes $^{\mathrm{b}}$ \\
\hline $\begin{array}{l}\text { Marchand et al. } \\
\text { (2017); OLS }\end{array}$ & $\begin{array}{l}\text { Video } \\
\text { games }\end{array}$ & No & No & Yes & Yes & No & Yes & No & Yese $^{\mathrm{e}}$ \\
\hline $\begin{array}{l}\text { Houston et al. } \\
\text { (2018); SEM }\end{array}$ & Movies & No & No & Yes & No & No & Yes & Yes & No \\
\hline $\begin{array}{l}\text { Basuroy et al. 2019; } \\
\text { GMM, OLS, IV }\end{array}$ & Movies & No & No & Yes & Yes & No & No & No & Yes $^{f}$ \\
\hline $\begin{array}{l}\text { Bogaert et al. 2021; } \\
\text { Machine learning }\end{array}$ & Movies & No & No & No & Yes & No & Yes & Yes & Yes $^{b}$ \\
\hline This paper; OLS & $\begin{array}{l}\text { Video } \\
\text { games }\end{array}$ & Yes & Yes & Yes & Yes & Yes & Yes & Yes & Yesg \\
\hline
\end{tabular}

Notes. OLS: Ordinary least squares, SVM: Support vector machine. SEM: Structural equation model, GMM: Generalized method of moments, IV: Instrumental variables estimation

a. Amazon.com \&bn.com, b. YahooMovies, c. Rotten tomatoes \& YahooMovies, d. Videogames.com, e. Amazon and Metacritic f. Rotten tomatoes, g. Metacritic 